\title{
ANÁLISE DO MODELO DIGITAL DE ALTURA DERIVADO DE PERFILAMENTO LIDAR EM
} RELEVO MONTANHOSO

\author{
Analysis of Digital Height Model (DHM) derived from laser profiling in mountainous relief \\ Letícia da Cunha Mose Ferreira \\ Programa de Pós-Graduação em Engenharia de Biossistemas - UFF \\ leticiacmf@id.uff.br \\ Cristiane Nunes Francisco \\ Departamento de Análise Geoambiental - UFF \\ cristianenf@id.uff.br \\ Pedro José Farias Fernandes \\ Departamento de Geografia - UFF \\ pj_fernandes@id.uff.br
}

Enviado para publicação em 17/02/2020 e aceito em 22/04/2020

DOI: 10.12957/tamoios.2020.48507

\section{Resumo}

Este artigo tem como objetivo elaborar o Modelo Digital de Altura (MDA), através dos modelos gerados por interpolação dos dados provenientes de perfilamento LIDAR para, assim, verificar o desempenho do MDA na distribuição espacial da altura da vegetação em relação à topografia de uma área com relevo acidentado. A área de estudo está inserida na bacia hidrográfica do Rio Jacaré, Niterói, RJ, e apresenta 163 ha e amplitude altimétrica de $400 \mathrm{~m}$, coberta por fragmentos florestais em diversos estágios de regeneração. O sensor ALS-60, com comprimento de onda do feixe de $1.064 \mathrm{~nm}$, obteve cinco pontos por metro quadrado com ângulo de varredura entre $10^{\circ}$ e $15^{\circ}$ para obtenção dos dados por perfilamento a laser no levantamento de Niterói. Com base neste conjunto de dados, foram gerados os Modelo Digital de Superfície (MDS) e o Modelo Digital de Terreno (MDT), com $50 \mathrm{~cm}$ de resolução espacial, através do interpolador Inverso da Distância Ponderada (IDP) e, a seguir, o MDA foi gerado pela diferença entre estes dois modelos. Os resultados obtidos no MDA demonstraram que nas áreas com relevo suave e menor altitude, a altura dos alvos é menor, enquanto que, com o aumento da altitude e declividade, a altura dos alvos aumenta, no entanto na classe de maior altitude e relevo escarpado, a altura da vegetação volta diminuir, demonstrando que o MDA apresentam um padrão de distribuição espacial aliado à topografia. No entanto, a análise de correlação indicou que não há dependência estatística entre eles, o que demonstra o potencial dos dados da tecnologia LIDAR na estimativa das alturas da cobertura da vegetação.

Palavras-chave: LIDAR; altura; vegetação.

\begin{abstract}
This paper aims to elaborate the Digital Height Model (DHM), using the models generated by interpolation of the LIDAR data profiling, thus verifying the performance of the MDA in the spatial distribution of the height of vegetation in relation to the topography of an area with rugged relief. The study area is in the Jacaré river basin, Niterói, RJ, and has 163 ha and altimetric amplitude of $400 \mathrm{~m}$, covered by forest fragments in different stages of regeneration. The ALS-60 sensor, with a beam wavelength of $1.064 \mathrm{~nm}$, obtained five points per square meter with scanning angle between $10^{\circ}$ and $15^{\circ}$ to obtain the data by laser profiling. Based on this dataset, the Digital Surface Model (DSM) and the Digital Terrain Model (DTM) were generated, with $50 \mathrm{~cm}$ of spatial resolution, through the Weighted Distance Inverse (WDI) interpolator and, subsequently, the DHM was generated by the difference between these two models. The results obtained in the DHM showed that in the areas with smooth relief and lower altitude, the height of the targets is lower, while with the increase in altitude and slope, the height of the targets increases. However in the class of higher altitude and steep relief, the height of the vegetation decreases again, demonstrating that the DHM has a spatial distribution pattern combined with the topography. However, the correlation analysis indicated that there is no statistical dependence between the models, which demonstrates the potential of LIDAR data in estimating the heights of vegetation cover.
\end{abstract}

Keywords: LIDAR, height, vegetation. 


\section{Introdução}

O LIDAR (Light Detection and Ranging) baseia-se na tecnologia de Sensoriamento Remoto ativo para medir a diferença de tempo entre a emissão de um pulso de laser por um sensor e o registro do sinal refletido, após interceptação por um objeto alvo, como edificações, construções, vegetação ou o terreno, que está na trajetória da radiação (BALTSAVIAS, 1999). Este sistema objetiva, através das propriedades de reflexão da energia eletromagnética, estimar a distância entre o sensor/aeronave e os objetos/alvos na superfície terrestre, considerando tanto a linha do solo como o que se encontra acima dela (VERMA et al. 2016). O sistema LIDAR aerotransportado, portanto, possui a finalidade de mensurar a altitude de um determinado ponto a partir da estimativa da distância entre o sensor e a superfície, determinando a posição do local onde a superfície foi atingida pelo laser e, assim, fornecendo dados espaciais da topografia do terreno e de outros elementos, naturais ou artificiais, existentes na superfície mapeada (SCHIMALESKY, 2008).

A tecnologia LIDAR tornou-se uma importante ferramenta na área florestal e tem sido amplamente utilizada na elaboração de inventários florestais e na caracterização das principais informações sobre a estrutura vertical de florestas (GARCIA-GUTIERREZ et al., 2014). Segundo Martins et al. (2010), durante as últimas décadas, as técnicas de Sensoriamento Remoto têm sido amplamente estudadas para suprir a gestão florestal com dados precisos, bem como reduzir o alto custo da produção dos inventários florestais. A capacidade de mensurar a altura, além de derivar outras medidas dendrométricas, é uma primazia na aplicação da tecnologia LIDAR no levantamento de dados em áreas florestadas, pois permite a rápida obtenção de informações em 3D, o que possibilita, assim, a representação da estrutura horizontal e vertical das árvores (WEZYK, 2012). Esta tecnologia aplica-se, assim, aos mais variados estudos florestais, como estimativas médias de volume e altura de árvores, classificação de espécies florestais, medição do crescimento de florestas, identificação individual de árvores e delimitação de copas (DUBAYAH et al. 2000). Segundo Peinhopf (2012), a varredura a laser fornece uma nova abordagem ao inventário florestal tradicional, a partir da riqueza de informações que possibilita a otimização do trabalho em campo, para fins de coleta de dados, inspeção de recursos e tomada de decisão à gestão.

Um dos produtos derivados do processamento das informações do LIDAR é o Modelo Digital de Altura (MDA) (HYYPPÄ, 2001) que consiste na estimativa da altura da cobertura florestal calculada a partir da subtração das elevações do primeiro e do último retorno do sinal LIDAR (DUBAYAH et al., 2000). O primeiro retorno do pulso laser em áreas de cobertura florestal corresponde, na maioria dos casos, aos pontos mais altos das copas das árvores, fornecendo dados para geração do Modelo Digital de Superfície (MDS), enquanto o último retorno apresenta alta probabilidade de corresponder à superfície do terreno, possibilitando obtenção do Modelo Digital de Terreno (MDT). Da subtração entre os dois modelos, é gerado o MDA, que representa uma alternativa para a análise de cobertura vegetal, por produzir inventários com grande riqueza de informações e, assim, viabilizar o estudo em grandes áreas, devido a menor relação entre o tempo e os recursos investidos (CASTRO; CENTENO, 2005).

Os dados adquiridos a partir do sistema LIDAR correspondem a uma nuvem com elevado número de pontos de medições de distância representando a superfície onde o laser incidiu. As medições são constituídas por coordenadas x, y e z, que representam o terreno e as elevações que o compõe, correspondentes às feições naturais, como vegetação, e elementos não naturais, como edificações. Assim, os dados brutos obtidos pelo LIDAR devem ser submetidos a um processamento para discriminá-los de acordo 
com a posição altimétrica que ocupam na superfície. Este processamento, denominado como filtragem, assume diferentes hipóteses a respeito da estrutura do terreno no local, o que condiciona o princípio metodológico adotado pelo filtro e, consequentemente, afeta o seu desempenho (SITHOLE; VOSSELMAN, 2005). De acordo com Schimalski et al. (2009), os algoritmos de filtragem tendem a apresentar resultados satisfatórios quando aplicados a áreas de relevo mais suave, enquanto os terrenos inclinados e cobertos por vegetação são considerados crítioas para a perfeita separação das feições pertencentes à superfície e ao terreno.

Como resultado da filtragem, os pontos extraídos não recobrem totalmente a superfície do solo, assim, para geração de MDT ou MDS que representem a superfície em sua totalidade, faz-se necessária a interpolação dos pontos de LIDAR, com o propósito de criar uma grade na qual o valor de cada ponto formado por um par de coordenada $(x, y)$ descreva a altura do terreno ou da superfície. De acordo com Jawak et al. (2012), a técnica da interpolação consiste em um processo de estimar os valores de um atributo específico em áreas sem amostragens baseado nos valores dos atributos das áreas amostradas. É assim necessária quando se deseja inferir valores em localidades entre os pontos amostrados, com o objetivo de se obter uma representação contínua do fenômeno, sendo geralmente usada em modelagem, pois necessitam de valores contínuos para representar a superfície (OLIVEIRA, 2010).

O presente trabalho tem, então, como objetivo elaborar o Modelo Digital de Altura, através dos modelos gerados por interpolação dos dados provenientes de perfilamento LIDAR de uma área com relevo acidentado para, assim, verificar o desempenho do MDA na distribuição espacial da altura da vegetação em relação à topografia do terreno.

A área de estudo corresponde ao recorte de cerca de 163 hectares na bacia hidrográfica do Rio Jacaré (BHRJ) (Figura 1), pertencente à Macrobacia da Região Oceânica do município de Niterói - RJ, com cerca de 600 ha, corresponente a maior bacia contribuinte ao sistema lagunar Piratininga-Itaipu. Além de possuir cobertura aerofotogramétrica e dados de perfilamento a laser, esta bacia está coberta com a Floresta Ombrófila Densa em diversos estágios de regeneração, inserida em grande parte no Parque Estadual da Serra da Tiririca (PESET). O mosaico florestal da bacia do Rio Jacaré é resultado do desenvolvimento de atividades humanas ao longo do tempo além de transformações naturais. Nas áreas mais planas da bacia, parte da vegetação original foi derrubada dando lugar as áreas urbanas, concentradas no médio e baixo curso do rio e, na medida que se avança para o alto curso, tornam-se rarefeitas e há predominância das propriedades rurais (BAPTISTA, 2009). 


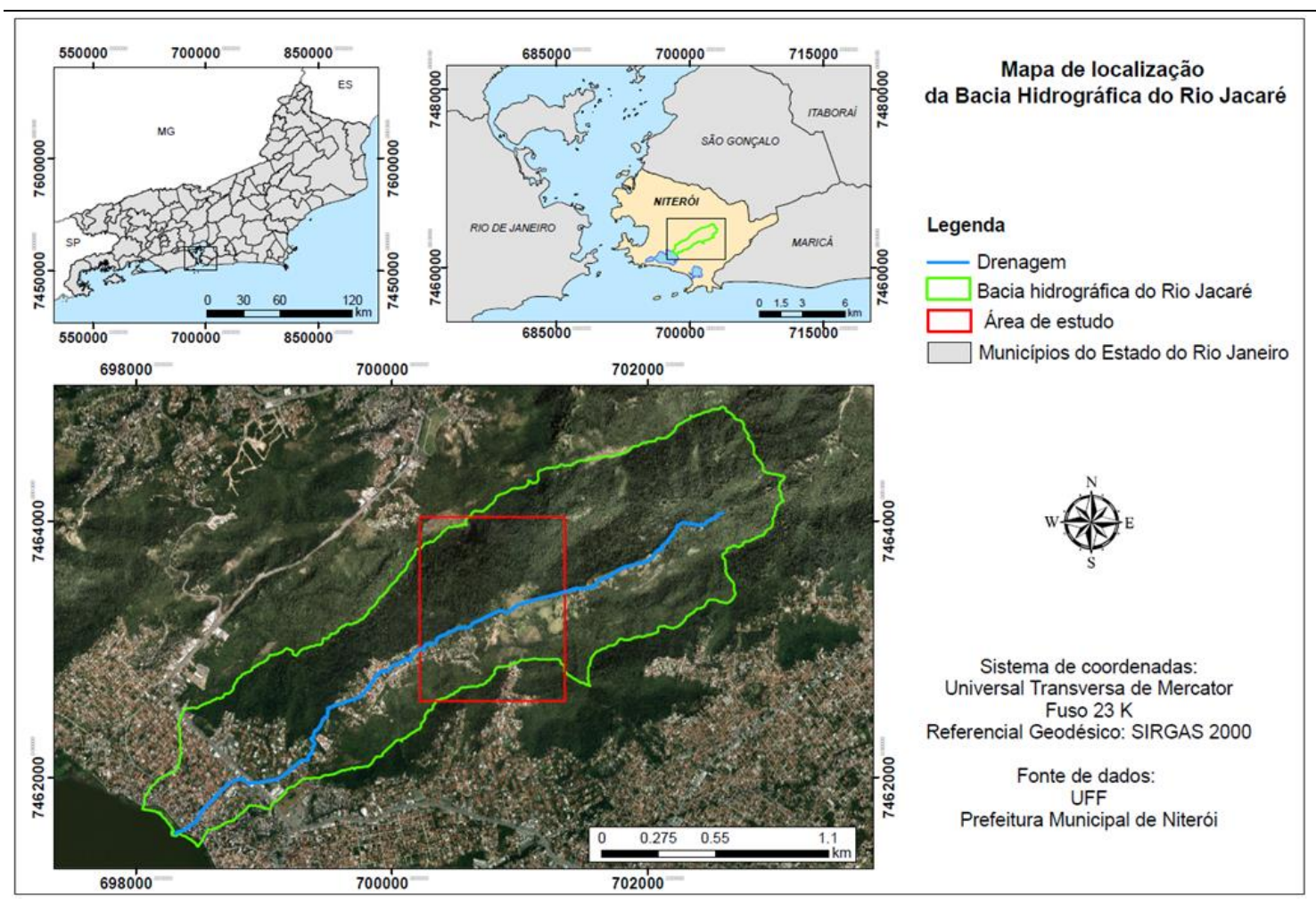

Figura 1 - Localização da área de estudo, Bacia Hidrográfica do Rio Jacaré, Niterói, RJ.

\section{Material e Métodos}

Os dados do perfilamento a laser foram adquiridos e tratados pela TOPOCART, que executou o levantamento no município de Niterói, realizado no mês de setembro de 2014 , com recobrimento de uma área de aproximadamente $140 \mathrm{~km}^{2}$. De acordo com a TOPOCART (2014), foi utilizado o sistema a laser aerotransportado modelo ALS-60, instalado em uma aeronave modelo SENECA, que opera em conjunto com a câmera de médio formato RCD 105. O sistema ALS-60 possui a característica de realizar o registro de múltiplos retornos, o que possibilita determinar a altura de objetos que estejam sobre a superfície mapeada. Este sensor trabalha com comprimentos de onda do feixe $1.064 \mathrm{~nm}$, opera com uma frequência de captação de pontos de $200 \mathrm{kHz}$ e possui amplitude operacional de $200 \mathrm{~s}$ a $5.000 \mathrm{~m}$, com abertura máxima do ângulo de visada de $75^{\circ}$. O voo teve altura variada, com média de $1.900 \mathrm{~m}$, e velocidade média de $120 \mathrm{~km} / \mathrm{h}$, obtendo 5 pontos por metro quadrado com ângulo de varredura entre $10^{\circ}$ e $15^{\circ}$ em função do relevo e da altura de voo.

Ainda de acordo com a TOPOCART (2014), os dados brutos dos sinais de retorno obtidos pelo sistema LIDAR, constituídos por um conjunto das coordenadas tridimensionais, foram processados com o sistema TerraScan-Terrasolid. Primeiramente, através da filtragem, realizou-se a identificação dos pontos, de acordo com a posição altimétrica que ocupam na superfície, dando origem a dois arquivos. Um deles constituiuse dos pontos derivados da superfície nua do terreno, isto é, sem as feições das elevações, correspondendo ao último pulso de retorno e, assim, aos valores altimétricos. O outro arquivo continha os pontos da superfície, ou seja, com valores de altimetria somada aos valores de elevação dos alvos presentes sobre a superfície terrestre, como edificações e copa das árvores, correspondendo, assim, ao primeiro pulso de retorno.

Com base, então, neste conjunto de dados, produzido pela TOPOCART (2014), a primeira etapa deste trabalho consistiu na geração dos modelos digitais através da interpolação. Foram gerados dois modelos, com resolução espacial de $50 \mathrm{~cm}$, um 
contendo os pontos altimétricos do terreno, correspondendo ao MDT, e o outro representando os pontos da superfície, correspondendo ao MDS.

O algoritmo de interpolação utilizado foi Inverso da Distância Ponderada (IDP), uma vez que não estima valores diferentes daqueles já existentes (ESRI, 2016), além de consumir menor tempo no processamento de uma alta densidade de dados. O IDP estima os valores de um atributo de pontos não amostrados a partir de uma combinação linear de valores dos pontos amostrados, através de uma função inversa à distância entre o ponto a ser calculado e os pontos amostrados (LI; HEAP, 2008). O pressuposto é de que os pontos amostrados próximos aos pontos não amostrados são mais similares do que aqueles mais distantes, ou seja, o modelo baseia-se na dependência espacial, partindo da suposição de que quanto mais próximo estiverem os pontos, maior é a correlação entre eles, atribuindo, assim, maior peso às amostras mais próximas do que para as mais distantes do ponto a ser interpolado.

Após a geração dos modelos, foi elaborado o MDA a partir do cálculo da diferença entre os MDS e MDT. A grade, resultado da subtração, apresenta a elevação dos objetos do terreno, ou seja, a altura da vegetação, considerando que, na área de estudo, predomina a cobertura florestal (Figura 2).

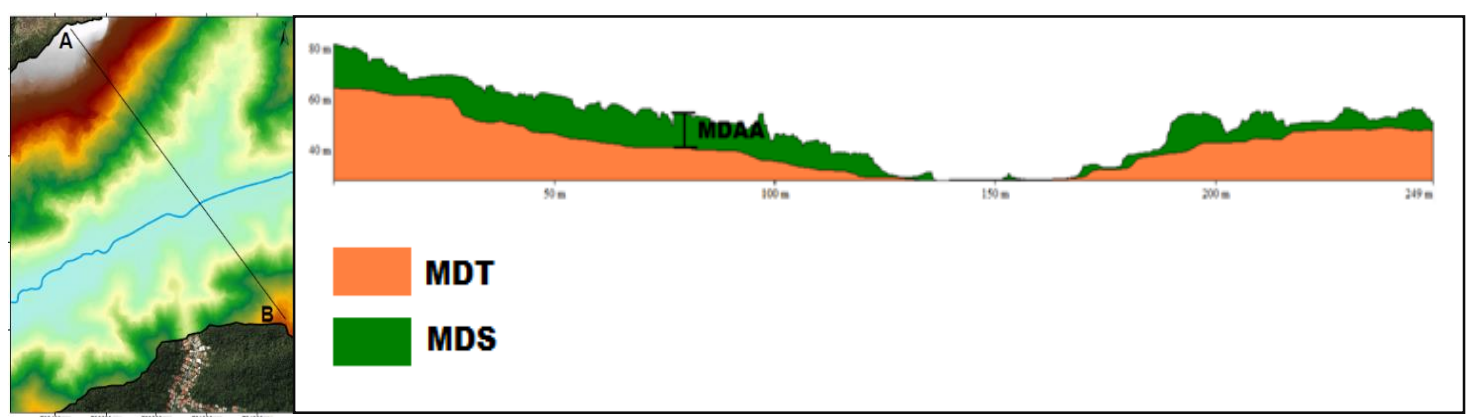

Figura 2 - Perfil longitudinal dos MDT, MDS e MDA da bacia hidrográfica do Rio Jacaré, Niterói, RJ.

Para fins de análise dos resultados, foi feita a classificação do MDA em sete classes considerando a altura da vegetação, de acordo com a Resolução CONAMA n ${ }^{\circ}$. 004/1994, que estabelece definições e parâmetros mensuráveis para análise de sucessão ecológica da Mata Atlântica no estado do Rio de Janeiro, conjuntamente com a classificação da vegetação proposta por Jennings et al. (2006) (Tabela 1).

Por fim, para estudar a relação entre a altura da vegetação e a topografia do terreno, ou seja. a relação de dependência estatística, foi feita a análise de correlação, calculada a partir do software $R$, entre os valores de altura da vegetação, obtidos no MDA, e os valores da altimetria e da declividade, obtidos no MDT. 
Tabela 1 - Classificação do MDA de acordo com a altura da vegetação.

\begin{tabular}{c|c|c}
\hline Altura (m) & Descrição das classes & Imagem \\
\hline Até 0 & Solo descoberto (afloramento, solo exposto) & \\
\hline $0-0,5$ & Vegetação Herbácea & \\
\hline $0,5-1$ & Vegetação Herbácea/Subarbustiva & \\
\hline $1-5$ & Vegetação Subarbustiva/Arbustiva & \\
\hline $5-12$ & Vegetação Arbustiva/Arbórea & \\
\hline $12-20$ & Vegetação Arbórea Média & \\
\hline$>20$ & Vegetação Arbórea Alta & \\
\hline
\end{tabular}

\section{Resultados}

De acordo com os resultados obtidos pelo MDA, observa-se que a classe predominante, com altura entre 5 e $12 \mathrm{~m}$ e mediana de $9 \mathrm{~m}$, está relacionada com a vegetação arbustiva/arbórea, representando $41 \%$ da área de estudo (Figura 3 e Figura 4). Presente em $21 \%$ da área de estudo, encontra-se a classe de altura de 1 a 5 m, mediana de $4 \mathrm{~m}$, correspondente à vegetação subarbustiva/arbustiva e à ocupação urbana, acompanhada da vegetação arbórea média, com altura entre 12 e 20 metros, mediana 14 $\mathrm{m}$, presente também em $20 \%$ da área de estudo.

A classe com menor frequência corresponde à vegetação arbórea alta, representando $2 \%$ da área de estudo, restrita a indivíduos com mais de $20 \mathrm{~m}$ de altura, mediana de $22 \mathrm{~m}$, e localizados majoritariamente na vertente sul da área de estudo. Enquanto os valores até 0 metro, correspondendo também $2 \%$ da área de estudo, estão associados a áreas de solo descoberto, ou seja, sem cobertura vegetal, como afloramentos rochosos nas encostas de forte de declive, bem como referem-se às áreas de pastagem. As classes correspondentes à vegetação herbácea e vegetação herbácea/subarbustiva, com menos de $1 \mathrm{~m}$ de altura, compreendem $14 \%$ da área de estudo e estão associadas à presença antrópica, localizadas predominantemente na vertente norte e na planície fluvial. 


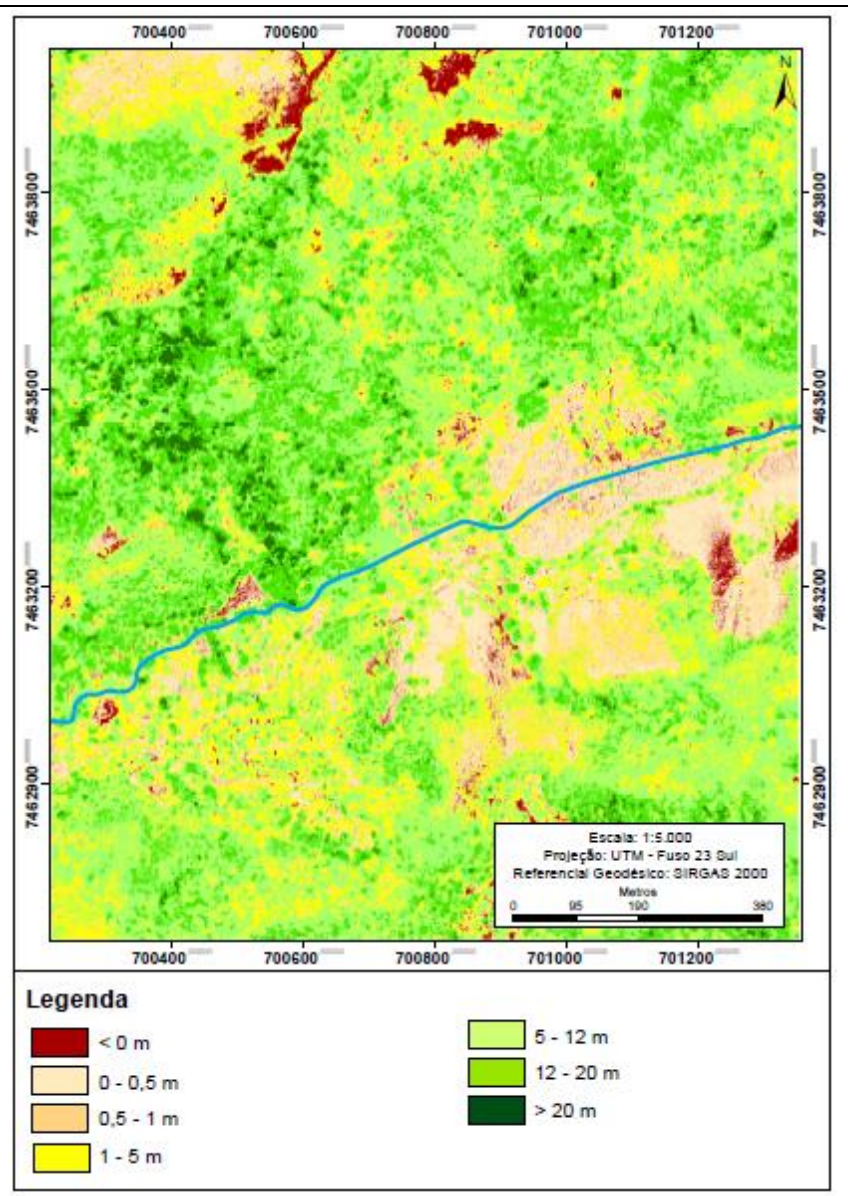

Figura 3 - Modelo Digital de Altura da bacia hidrográfica do Rio Jacaré, Niterói, RJ.

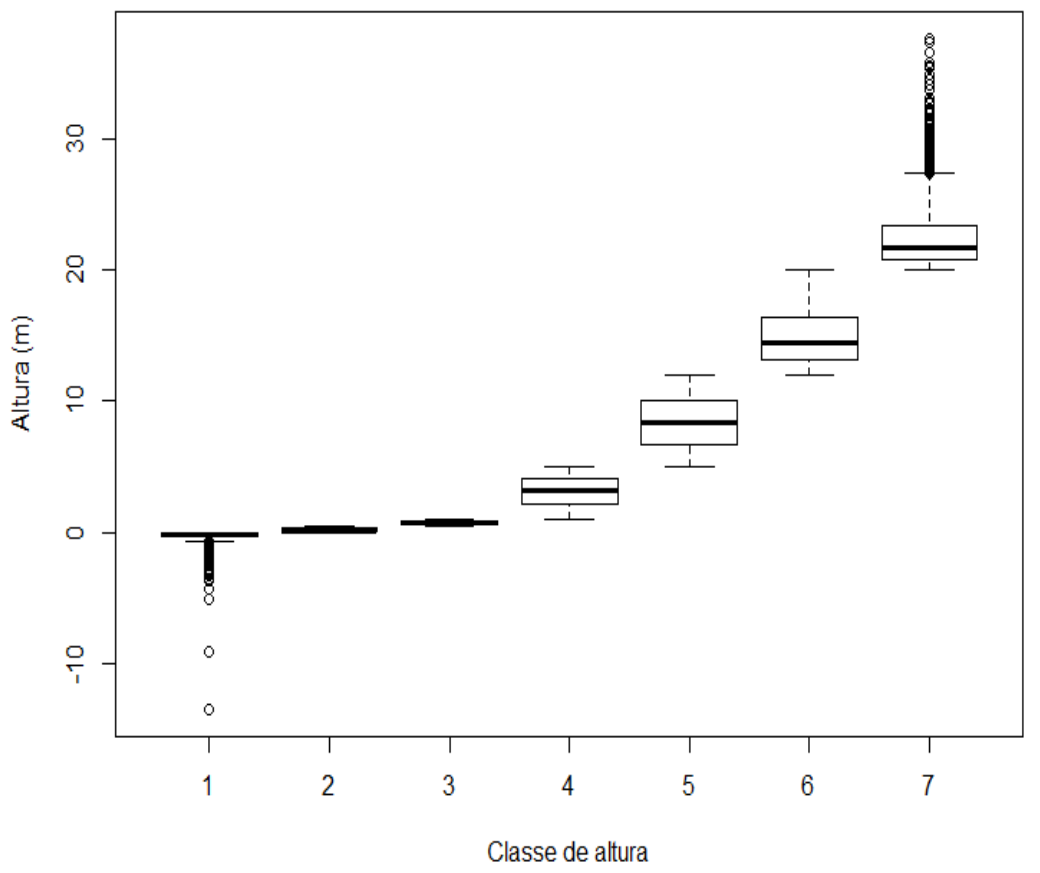

Figura 4 - Altura da vegetação de bacia hidrográfica do Rio Jacaré, Niterói, RJ. 


\begin{tabular}{ccc}
\hline \multicolumn{3}{c}{ Tabela 2 - Classes de cobertura da terra } \\
\cline { 2 - 4 } Altura $(\mathbf{m})$ & Classe & Área (\%) \\
\hline Até 0 & 1- Solo descoberto & 2,2 \\
$0-0,5$ & 2- Vegetação herbácea & 10,5 \\
$0,5-1$ & 3- Vegetação herbácea/subarbustiva & 3,5 \\
$1-5$ & 4- Vegetação herbácea/arbustiva & 20,8 \\
$5-12$ & 5- Vegetação arbustiva/arbórea & 40,6 \\
$12-20$ & 6- Vegetação arbórea média & 20,3 \\
$>20$ & 7- Vegetação arbórea alta & 2,1 \\
\hline
\end{tabular}

A análise entre o MDA e a altimetria demonstra que o aumento da altitude é acompanhado pelo aumento da média de altura dos alvos, passando de 5 para $9 \mathrm{~m}$, respectivamente, nos intervalos altimétricos de 16 a $300 \mathrm{~m}$ (Figura 5). Este crescimento é interrompido na última classe altimétrica, com intervalo entre 300 e $408 \mathrm{~m}$, onde a altura média passa a ser $7 \mathrm{~m}$, possivelmente pela predominância da vegetação mais baixa, devido a solos mais rasos, próximos aos topos de morros e, até mesmo, da presença da vegetação rupestre nos afloramentso rochosos. A classe de menor altitude (16 - $30 \mathrm{~m})$, localizada no terreço fluvial do Rio Jacaré, apresenta a menor média da altura dos alvos, correspondente a $5 \mathrm{~m}$, que pode ser explicado pela predominância da vegetação herbácea e arbustiva, uma vez que esta área possui maior presença das atividades humanas. Nas demais classes, entre 30 e $300 \mathrm{~m}$ de altitude, o aumento na média de altura dos alvos pode estar associada à predominância de vegetação arbustiva a arbórea. 


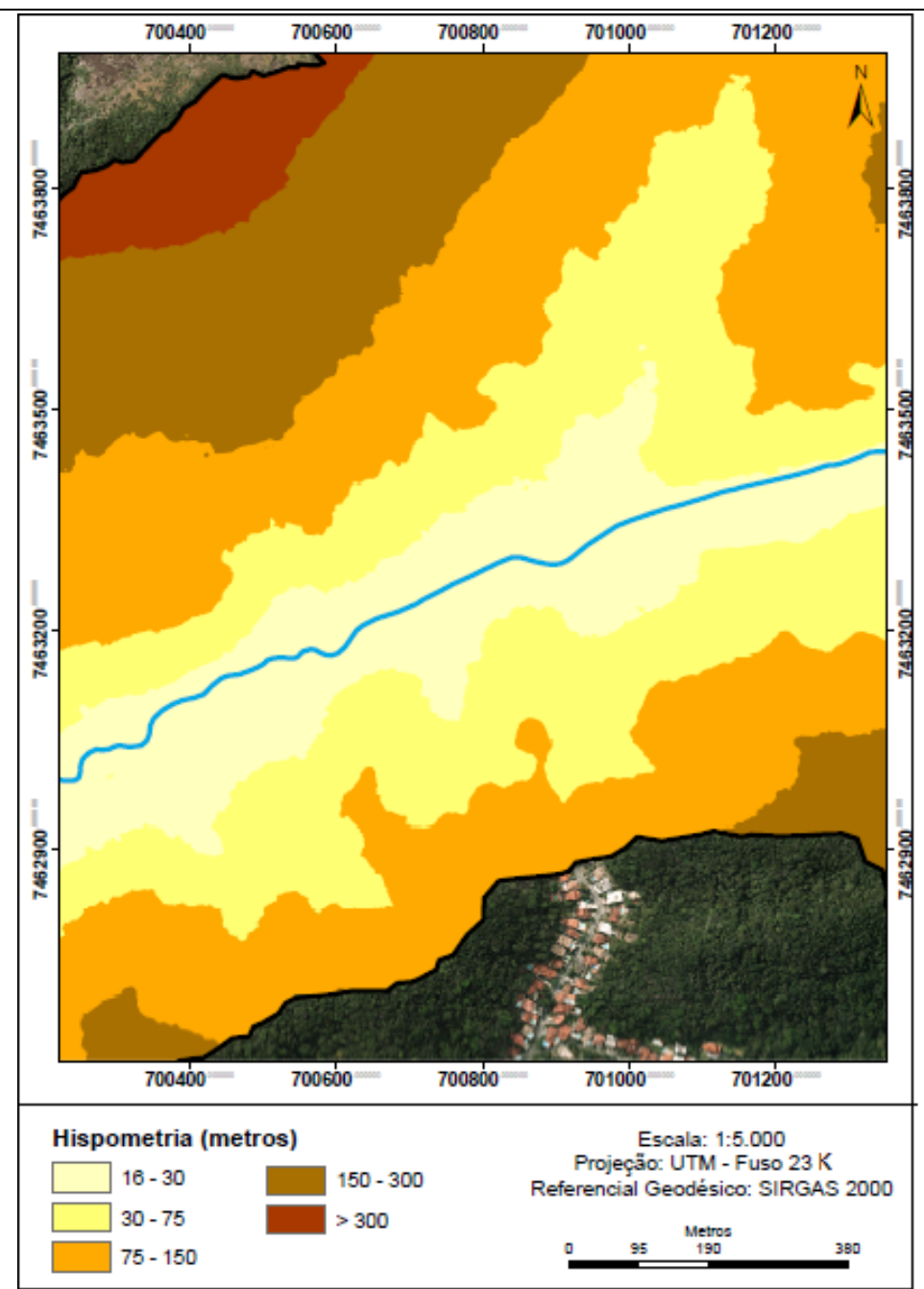

Figura 5 - Hipsometria da bacia hidrográfica do Rio Jacaré, Niterói, RJ.

Tabela 3 - Média da altura da vegetação por faixa de altitude.

\begin{tabular}{cc}
\hline $\begin{array}{c}\text { Faixa de altitude } \\
(\mathbf{m})\end{array}$ & $\begin{array}{c}\text { Média da altura da } \\
\text { vegetação }(\mathbf{m})\end{array}$ \\
\hline $16-30$ & 5,0 \\
$30-75$ & 7,1 \\
$75-150$ & 8,4 \\
$150-300$ & 8,9 \\
$300-408$ & 6,7 \\
\hline
\end{tabular}

O coeficiente de correlação $\left(\mathrm{R}^{2}=0,002\right.$ e $\left.\mathrm{p}<0,05\right)$ e a análise do gráfico de dispersão entre a altitude (MDT) e altura dos alvos (MDA) de toda área de estudo indicam que a variação da altura não é explicada pela variação da altitude, ou seja, não existe relação funcional entre a variável dependente e a variável independente, logo o padrão identificado na distribuição da altura dos alvos pelas classes de altitude é decorrente da relação entre as duas variáveis e não em função da variação dos modelos (Figura 5). 


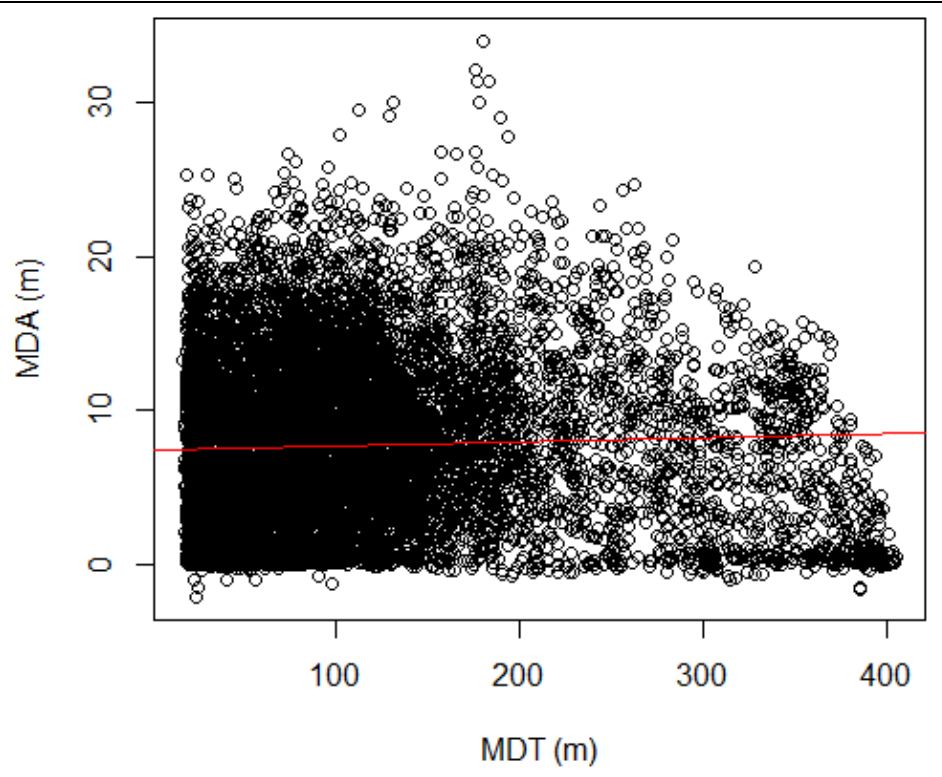

Figura 6 - Gráfico de dispersão entre o MDT e MDA da bacia hidrográfica do Rio Jacaré, Niterói, RJ.

A análise entre o MDA e a declividade demonstra que a média da altura dos alvos nas áreas com declividade plana ou suavemente ondulada $\left(0\right.$ a $\left.4,6^{\circ}\right)$ é a menor, correspondendo a $3,2 \mathrm{~m}$, devido, possivelmente, ao desenvolvimento de atividades antrópicas nessas áreas, com a presença das áreas urbanas e atividades agrícolas, que interferem e alteram as características da vegetação nativa (Figura 7). Verifica-se, também, que a média de altura acompanha o aumento da declividade da área de estudo, passando de 3,2 $\mathrm{m}$ para $8 \mathrm{~m}$ do relevo plano ao montanhoso, uma vez que, a inclinação do terreno impõe dificuldades para o estabelecimento das atividades humanas, diminuindo, então, as alterações e possibilitando o desenvolvimento da vegetação. As classes de relevo fortemente ondulado e montanhoso $\left(11,4^{\circ}\right.$ a $\left.45^{\circ}\right)$ correspondem a cerca de $80 \%$ da área de estudo e apresentam os estratos mais altos de vegetação com média de $8 \mathrm{~m}$ de altura. No entanto, nas áreas com relevo escarpado, ou seja, acima de $45^{\circ}$, ocorre a redução da média da altura da vegetação, atingindo $5 \mathrm{~m}$, possivelmente, nestas áreas, o solo pouco espesso não propicia o desenvolvimento da vegetação.

Da mesma forma, o coeficiente de correlação $\left(\mathrm{R}^{2}=0,01\right.$ e $\left.\mathrm{p}<0,05\right)$ e a análise do gráfico de dispersão entre a declividade e altura dos alvos (MDA) de toda área de estudo apontam que os valores de altura dos alvos não variam em decorrência da variação declividade (Figura 7), demonstrando, assim, que não existe relação funcional entre a variável dependente com a variável independente, logo o padrão identificado na distribuição da altura dos alvos pelas classes de declividade é decorrente da relação entre as duas variáveis e não em função da variação dos modelos. 


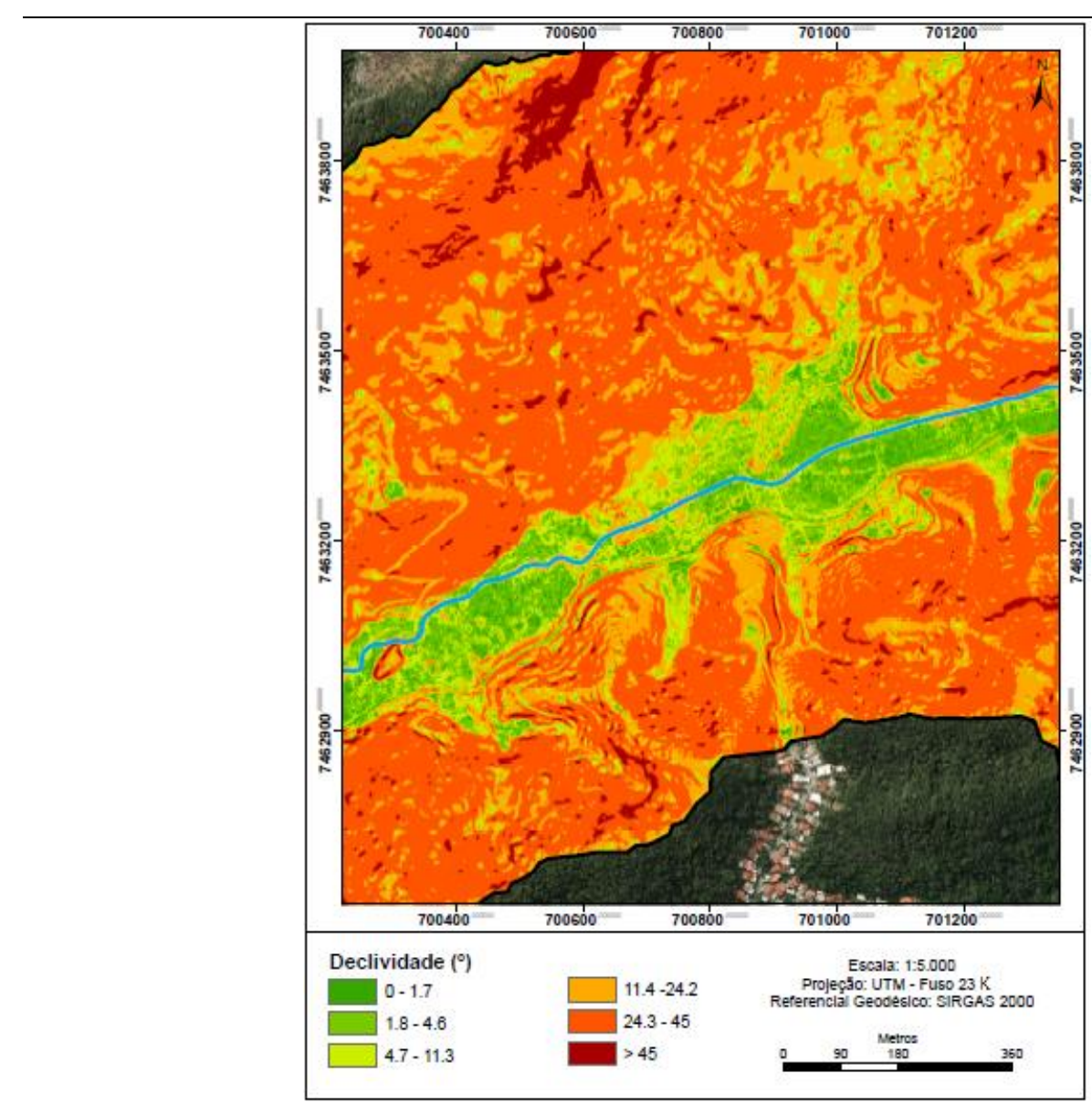

Figura 7 - Mapa de declividade da bacia hidrográfica do Rio Jacaré, Niterói, RJ.

Tabela 5 - Classes de declividade por média de altura.

\begin{tabular}{|c|c|c|}
\hline Declividade & Relevo & Média de altura (m) \\
\hline $0-1,7^{\circ}$ & Plano & 3,2 \\
\hline $1,8-4,6^{0}$ & Suave ondulado & 4,2 \\
\hline $4,7-11,3^{\circ}$ & Ondulado & 6,1 \\
\hline $11,4-24,2^{\circ}$ & Forte ondulado & 8,1 \\
\hline $24,3-45^{\circ}$ & Montanhoso & 8,0 \\
\hline$>\mathbf{4 5}^{\circ}$ & Escarpado & 5,5 \\
\hline
\end{tabular}




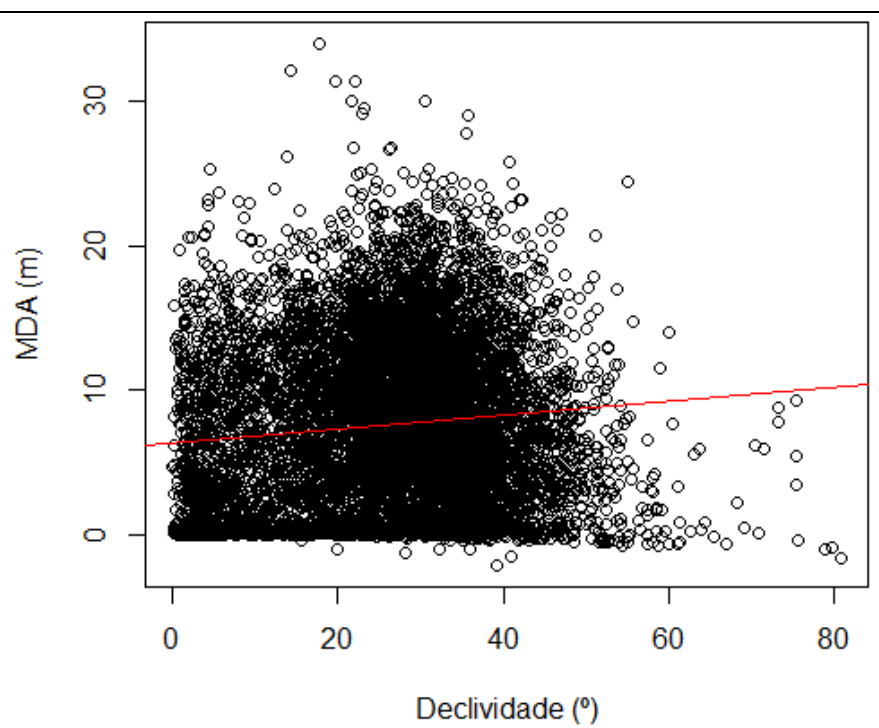

Figura 8 - Gráfico de dispersão da declividade e MDA da Bacia Hidrográfica do Rio Jacaré, Niterói, RJ.

\section{Conclusões}

Os resultados obtidos no MDA demonstraram que a área de estudo apresenta variação de altura dos alvos acima de $20 \mathrm{~m}$. Nas áreas com relevo suave e próximas ao canal principal, correspondente menor altitude, a altura é menor, devido à presença das atividades humanas, enquanto que, com o aumento da altitude e declividade, a altura dos alvos aumenta, atingindo média próxima a $9 \mathrm{~m}$, devido à presença da vegetação de estrato maior. No entanto, na classe de maior altitude e relevo escarpado, a altura da vegetação diminui, atingindo valor próximo a $6 \mathrm{~m}$. Verifica-se, assim, que, na área de estudo, os dados de altura derivados do MDA apresentam um padrão de distribuição espacial aliado à topografia. No entanto, a análise de correlação entre a topografia e o MDA indicou que não há dependência estatística entre eles, demonstrando, assim, o potencial dos dados da tecnologia LIDAR na estimativa das alturas de árvores individuais ou de ambientes florestais.

\section{Referências Bibliográficas}

BALTSAVIAS, E. P. Airbone Laser Scanning: basic relations and formulas. ISPRS Journal of Photogrammetry and Remote Sensing, v. 54, p.199-214, 1999.

BAPTISTA, J.V; FERNANDES, V.F. Alterações ambientais em decorrência do processo de urbanização acelerada na bacia hidrográfica do Rio Jacaré, Niterói - RJ. In: II Seminário de Recursos Hídricos da Bacia Hidrográfica do Paraíba do Sul: Recuperação de Áreas Degradadas Serviços Ambientais e Sustentabilidade, Taubaté, 2009, IPABHi, p. 537-544.

CASTRO, F.C; CENTENO, T.M. Segmentação de imagens geradas por perfilamento a laser para delimitação de árvores individuais em uma área de reflorestamento de eucaliptos. In: XII Simpósio Brasileiro de Sensoriamento Remoto, Goiânia, Brasil, 16-21 abril 2005, INPE, p. 737744.

DUBAYAH, R.; KNOX, R.; HOFTON, M.; BLAIR, J. B.; DRAKE, J. Land surface characterization using LiDAR remote sensing. In: HILL, M. e ASPINALL, R. (Ed.). Spatial Information for Land Use Management. Singapore: International Publishers Direct, 2000.

DUBAYAH, R.O.; DRAKE, J.B. Lidar remote sensing for forestry. Journal of Forestry, v. 98, p. 44-46, 2000.

ESRI, Enviromental Systems Research Institute. Html Help Control Version 10, disponível:<http://help.arcgis.com/en/arcgisdesktop/10.0/help/index.html\#//009z0000007m0000 00.htm>, acessado em fevereiro de 2016. 
GARCIA-GUTIERREZ, J.; GONZALEZ-FERREIRO, E.; RIQUELME-SANTOS, JC.; MIRANDA, D.; DIEGUEZ-ARANDA. U.; NAVARRO-CERRILLO, RM. Evolutionary feature selection to estimate forest stand variables using LiDAR. International Journal Applied Earth Observation and Geoinformation, v. 26, p 119-131, 2014.

HYYPPA, J.; KELLE, O.; LEHIKOINEN, M.; INKINEN,M. A segmentation- based method to retrieve stem volume estimates from 3-D tree height models produced by laser scanners. IEEE Transaction on Geoscience and Remote Sensing, v. 39, n. 5, p. 969-975, 2001.

JAWAK, S.D., SAMBHUS, P.G, PARANJAPE, R.A. and LUIS, A.J. (2012) Assessment of Spatial Interpolation Techniques for Generating Accurate Digital Elevation Surface Using Combined Radar \& LiDAR Elevation Data. Proceedings of 8th International Conference on Microwaves, Antenna Propagation and Remote Sensing (ICMARS), Jodhpur, 11-15 December 2012, 288-291.

JENNINGS, M.D.; FABER-LANGENDOEN, D.; PEET, R.K.; LOUCKS.; O.L., D.C. GLENNLEWIN, A. DAMMAN, M.G.Barbour, R. Pfister, D.H. Grossman, D. Roberts, D. Tart, M. Walker, S.S. Talbot, J. Walker, G.S Hartshorn, G. Waggoner, M.D. Abrams, , A. Hill, M. Rejmanek. 2006. Description, Documentation, And Evaluation Of Associations And Alliances Within The U.S. National Vegetation Classification, Version 4.5. Ecological Society of America, Vegetation Classification Panel. Washington DC. 119p.

LI, J.; HEAP, A.D., 2008. A Review of Spatial Interpolation Methods for Environmental Scientists. Geoscience Australia, Record 2008/23, 137 pp.

MARTINS, F. S. R.V.; BOCK, J.; DAMBRINE, E.; DEZ, G.; DUPOUEY, J.; GEORGESLEROY, M.; JOLLY, A.; RENAUD, J. Estimating dominant height in deciduous stands using multi-echo LIDAR data. Ambiência, v.6 (Especial), p 115-126, 2010.

OLIVEIRA, G.G. DE. Modelos para previsão, espacialização e análise das áreas inundáveis na bacia hidrográfica do rio caí, RS. Dissertação de mestrado. UFRGS - Universidade Federal do Rio Grande do Sul. Programa de Pós-Graduação em Sensoriamento Remoto. Porto Alegre, RS. 2010.

PEINHOPF, C. Determinação de Variáveis Dendrométricas de Eucalyptus Urograndis Com Dados Lidar Aerotransportado. Dissertação (Mestrado em Ciências Florestais). Universidade Estadual do Centro-Oeste - UNICENTRO, Irati-PR.

SCHIMALESKY, V.; CENTENO, J. A. S. Avaliação da qualidade da informação altimétrica derivada da varredura a laser em uma região coberta por vegetação: estudo de caso. Floresta, v.38, p. 597-606, 2008.

SITHOLE G., VOSSELMAN G.: Comparison of filtering algorithms. In Proceedings of the ISPRS working group III/3 workshop "3-D reconstruction from airborne laserscanner and InSAR data" (Dresden, Germany, 2003), Maas H.- G., Vosselman G., Streilein A., (Eds.), International Archives of Photogrammetry and Remote Sensing, Vol. XXXIV, 3/W13, pp. 71-78.

TOPOCART. Relatório Técnico Final Levantamento Aerofotogramétrico e Perfilamento a Laser Niterói - RJ. Brasília: Topocart. 2014.

VERMA, N. K.; LAMB, D.W.; REID, N.; WILSON, B. Comparison of canopy volume measurements of scattered eucalypt farm trees derived from high spatial resolution imagery and LIDAR. Remote Sensing, v. 8, p. 388, 2016.

WEZYK, P. The integration of the terrestrial and airbone laser scanning technologies in the semiautomated process of retrieving selected tress and forest stand parameters. Ambiência, v.8, p. 533-548, 2012. 